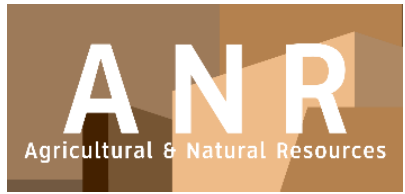

PAPER - OPEN ACCESS

\title{
Deteksi Deforestasi Menggunakan Citra Satelit Resolusi Tinggi Pada Lanskap Hutan Mangrove Percut Sei Tuan
}

\author{
Author : Nurdin Sulistiyono \\ DOI $\quad: 10.32734 /$ anr.v1i2.239 \\ Electronic ISSN : 2654-7023 \\ Print ISSN : 2654-7015
}

Volume 1 Issue 2 - 2018 TALENTA Conference Series: Agricultural \& Natural Resources (ANR)

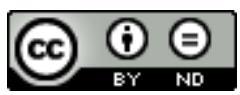

This work is licensed under a Creative Commons Attribution-NoDerivatives 4.0 International License.

Published under licence by TALENTA Publisher, Universitas Sumatera Utara
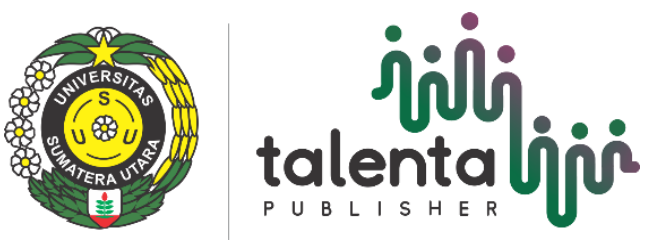


\section{inji} talenta

Available online at https://talentaconfseries.usu.ac.id

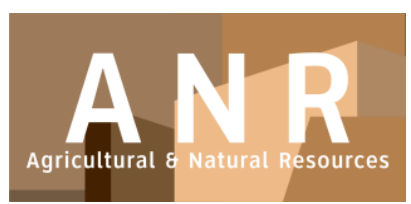

\title{
Deteksi Deforestasi Menggunakan Citra Satelit Resolusi Tinggi Pada Lanskap Hutan Mangrove Percut Sei Tuan
}

\author{
Nurdin Sulistiyono $^{\mathrm{a}^{*}}$, Pindi Patana ${ }^{\mathrm{a}}$, Achmad Siddik Thoha $^{\mathrm{a}}$, Khairil Amri ${ }^{\mathrm{a}}$, Onrizal ${ }^{\mathrm{b}}$ \\ ${ }^{a}$ Fakultas Kehutanan, Universitas Sumatera Utara, Medan, Indonesia
}

nurdinsty2013@gmail.com

\begin{abstract}
Abstrak
Hutan mangrove telah diketahui memiliki peran penting sebagai penyangga kehidupan kawasan pantai dan mata rantai penghubung ekosistem daratan dan ekosistem laut. Namun demikian tekanan terhadap lanskap hutan mangrove dirasakan semakin besar tiap tahunnya dalam bentuk deforestasi. Pemanfaatan citra satelit resolusi tinggi dari Google Earth dapat digunakan untuk kegiatan monitoring lanskap hutan mangrove dalam skala yang lebih detail. Penelitian ini bertujuan untuk mengidentifikasi deforestasi serta kesesuaian pola peruntukan ruang pada lanskap hutan mangrove di Percut Sei Tuan pada periode tahun 2011 - 2016. Pendekatan metodelogi yang digunakan adalah dengan menggunakan post classificaion comparism dengan metode on screen pada citra satelit dari google earth. Hasil penelitian menunjukan besarnya laju deforestasi pada lanskap hutan mangrove sebesar 77,43ha atau sebesar 15,43 ha/tahun. Penggunaan lahan pada lanskap hutan mangrove di Percut Sei Tuan pada tahun 2011 dan 2016 tidak sesuai dengan peruntukan lahan sebagaimana yang tercantum dalam Rencana Tata Ruang Wilayah Kabupaten Deli Serdang.
\end{abstract}

\section{Pendahuluan}

Hutan mangrove telah diketahui memiliki peran penting sebagai penyangga kehidupan kawasan pantai dan mata rantai penghubung ekosistem daratan dan ekosistem laut. Oleh karena itu, keberadaan hutan mangrove yang merupakan bagian dari ekosistem pantai harus tetap dipertahankan guna memperoleh manfaat sebesar-besarnya bagi kehidupan manusia secara lestari. Namun demikian tekanan terhadap lanskap hutan mangrove dirasakan semakin besar tiap tahunnya. Sekitar $80 \%$ dari 1.000 .000 ha kehilangan mangrove Indonesia disebabkan oleh perluasan tambak udang dan ikan [1]. Pada dua dasawarsa mendatang diperkirakan ekspansi tambak dan perluasan perkebunan kelapa sawit masih menjadi faktor utama kehilangan mangrove Indonesia [2].

Konversi lahan mangrove menjadi penggunaan lahan lain ini juga marak terjadi di Pesisir Timur Sumatera Utara seperti di Percut Sei Tuan. Selain kaya akan hasil laut, Percut Sei Tuan juga merupakan habitat penting bagi berbagai jenis burung air dan telah diidentifikasi sebagai Daerah Penting bagi Burung [3]. Maraknya kegiatan perambahan dan konversi hutan mangrove ke areal penggunaan lain di Percut Sei Tuan telah mengakibatkan luas dan sebaran spasial tutupan hutan mangrove yang ada menjadi berubah.

Pemanfaatan citra satelit resolusi tinggi merupakan salah satu alternatif yang lebih efektif dan efisien yang dapat digunakan untuk memperoleh data mengenai sebaran spasial lanskap hutan mangrove termasuk ancamannya dalam bentuk deforestasi. Penelitian ini menjadi penting untuk dilakukan, mengingat belum adanya informasi besarnya deforestasi yang terjadi pada lanskap hutan mangrove di Percut Sei Tuan yang sangat diperlukan dalam penyusunan kegiatan perencanaan pengelolaan hutan mangrove. Penelitian ini bertujuan untuk mengetahui besarnya deforestasi 
dan kesesuaian penggunaan lahan dengan rencana peruntukan penggunaan lahan di lanskap hutan mangrove Percut Sei Tuan.

\section{Bahan dan Metode}

\subsection{Lokasi penelitian}

Penelitian ini dilakukan pada ekosistem mangrove di Kecamatan Percut Sei Tuan, Kabupaten Deli Serdang yang terdiri dari 3 buah desa yakni Desa Tanjung Rejo, Desa Percut dan Desa Pematang Lalang. Peta lokasi daerah penelitian dapat dilihat pada Gambar 1.

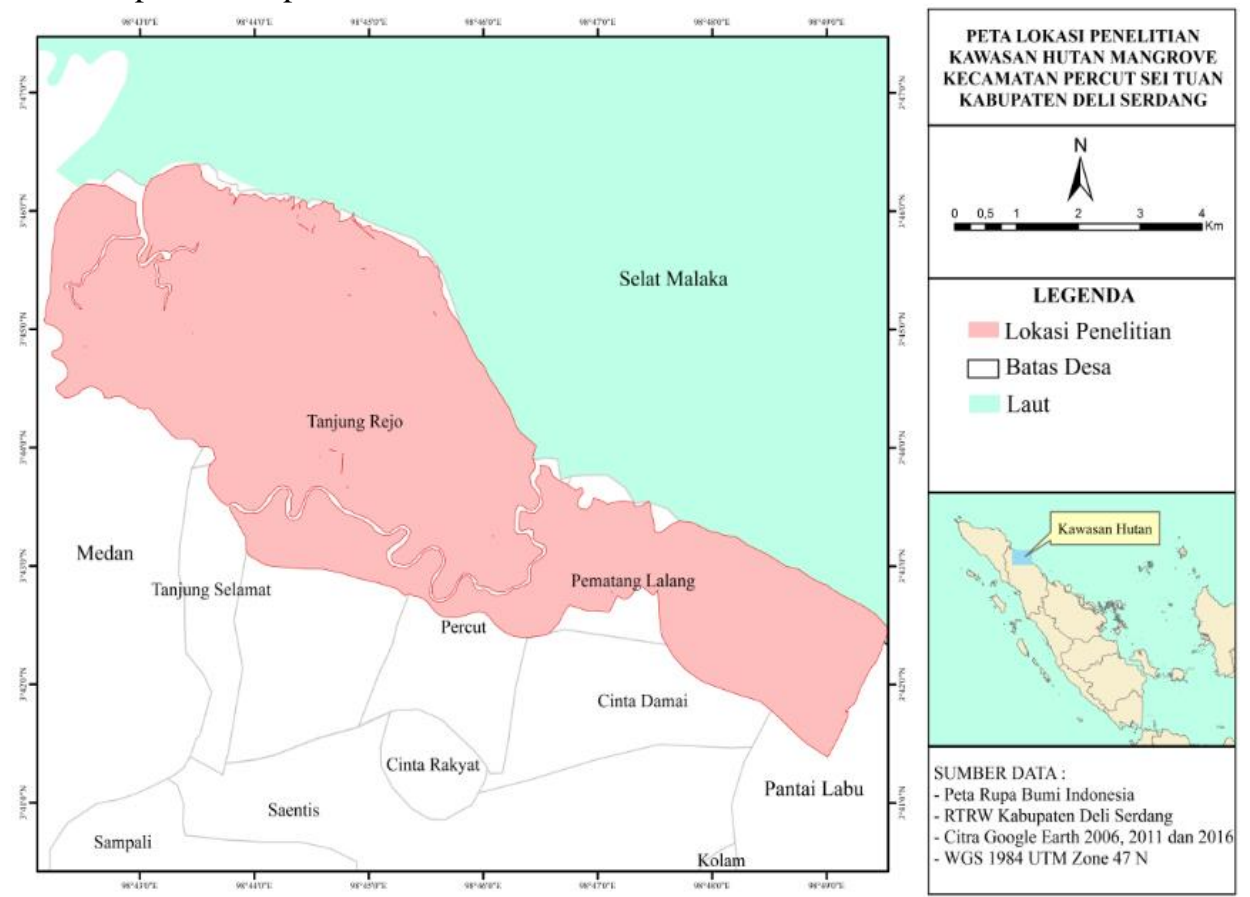

Gambar 1. lokasi penelitian dilakukan.

\subsection{Metode}

Penelitian ini dilakukan pada bulan Mei sampai September 2017. Alat digunakan pada penelitian ini yaitu kamera digital, sofware ArcGIS, GPS (Global Positioning system), dan computer, sedangkan bahan yang digunakan adalah Citra Satelit Quickbirdyang berasal dariGoogle Earthtahun 2006, 2011 dan 2016, serta peta Rencana Tata Ruang Wilayah Kabupaten Deli Serdang.

Metode mendigit langsung pada layar atau yang sering disebut on screen digitaizingmengacu pada penelitian Alkan et al [4] dan Abdelwahed et al [5]. Metode ini dilakukan untuk menentukan klasifikasi penutupan lahan pada daerah penelitian. Proses koreksi geometrik dilakukan dengan melakukan georeferece pada citra satelit dengan titik GPS yang diperoleh dari lapangan.

Proses validasi dilakukan pada penutupan lahan terakhir yakni penutupan lahan tahun 2016 dengan melakukan ground check penutupan lahan di lapangan. Penentuan besarnya nilai akurasi dari hasil klasifikasi penutupan lahan pada penelitian ini menggunakan matrik kesalahan mengacu pada penelitian Churches et al[6] dan Olofsson et al[7]. Persamaan Kappa Accuracy dengan rumus sebagai berikut : 


$$
\operatorname{Kappa}(\kappa)=\frac{N \sum_{k}^{r} X_{k k}-\sum_{k}^{r} X_{k+} X_{+k}}{N^{2}-\sum_{k}^{r} X_{k+} X_{+k}} \times 100 \%
$$

Dimana :

$\mathrm{N}=$ Jumlah semua piksel yang digunakan untuk pengamatan

$\mathrm{r} \quad=\quad$ Jumlah baris/lajur pada matriks kesalahan (jumlah kelas)

$\mathrm{X}_{\mathrm{kk}}=\quad$ Jumlah piksel pada kelas bersangkutan (pada diagonal matriks)

$\mathrm{X}_{\mathrm{k}+}=\quad \sum \mathrm{X}_{\mathrm{ij}}$ (jumlah semua kolom pada baris ke-i)

$\mathrm{X}_{+\mathrm{k}}=\quad \sum \mathrm{X}_{\mathrm{ij}}$ (jumlah semua kolom pada lajur ke-j)

\section{Hasil}

Hasil pengujian kappa accuracy untuk mengukur tingkat validitas klasifikasi penutupan lahan pada ekosistem mangrove tahun 2016 sebesar 95,21\%. Angka pengujian ini didapatkan dengan membandingkan hasil klasifikasi penutupan lahan dengan 121 titik groundcheck dengan GPS di lapangan.

Hasil klasifikasi penutupan lahan periode tahun 2011 sampai tahun 2016 menggunakan citra satelit resolusi tinggi dapat dilihat pada tabel 1, sedangkan hasil overlay antara penutupan lahan tahun 2016 dengan Rencana Tata Ruang Wilayah Kabupaten Deli Serdang Tahun 2010 - 2027 dapat dilihat pada tabel 2.

Tabel 1. Luas dan persentase perubahan tutupan lahan ekosistem mangrove Kecamatan Percut Sei Tuan

\begin{tabular}{llllll}
\hline \multirow{2}{*}{ No } & Penutupan Lahan & \multicolumn{2}{l}{ Luas (ha) } & \multicolumn{2}{l}{ Prosentase (\%) } \\
\cline { 3 - 5 } & & 2011 & 2016 & 2011 & 2016 \\
\hline 1 & Badan Air & 211,92 & 214,87 & 4,63 & 4,7 \\
2 & Lahan Terbuka & 5,9 & 44,67 & 0,13 & 0,98 \\
3 & Mangrove & $1.140,37$ & $1.062,94$ & 24,92 & 23,23 \\
4 & Mangrove Sawit & 0 & 7,03 & 0 & 0,15 \\
5 & Pemukiman & 51,59 & 53,52 & 1,13 & 1,17 \\
6 & Sawah & 623,37 & 476,68 & 13,62 & 10,42 \\
7 & Perkebunan Sawit & $1.211,44$ & $1.419,54$ & 26,48 & 31,02 \\
8 & Tambak & $1.218,49$ & $1.171,33$ & 26,63 & 25,6 \\
9 & Kebun Campuran & 112,39 & 124,9 & 2,46 & 2,73 \\
\hline & TOTAL & $4.575,48$ & $4.575,48$ & 100 & 100 \\
\hline
\end{tabular}


Tabel 2. Data Kesesuaian Rencana Tata Ruang Wilayah Kabupaten Deli Serdang dengan penutupan lahan ekosistem mangrove Tahun 2016

\begin{tabular}{lcccccccccc}
\hline Peruntukan & $\begin{array}{l}\text { Badan } \\
\text { Air }\end{array}$ & $\begin{array}{l}\text { Kebun } \\
\text { Campuran }\end{array}$ & $\begin{array}{l}\text { Lahan } \\
\text { Terbuka }\end{array}$ & $\begin{array}{l}\text { Mang- } \\
\text { rove }\end{array}$ & $\begin{array}{l}\text { Luas (Ha) } \\
\text { Mangrove } \\
\text { Sawit }\end{array}$ & $\begin{array}{l}\text { Pemu- } \\
\text { kiman }\end{array}$ & Sawah & Sawit & Tambak & Total \\
\hline $\begin{array}{l}\text { Hutan } \\
\text { Lindung }\end{array}$ & 119,46 & 66,60 & 39,95 & 580,82 & 7,03 & 27,00 & 98,85 & 359,52 & 783,61 & $2.082,83$ \\
$\begin{array}{l}\text { Hutan } \\
\begin{array}{l}\text { Produksi } \\
\text { Terbatas }\end{array}\end{array}$ & 33,53 & 1,06 & 1,70 & 320,42 & - & - & - & 490,45 & 234,89 & $1.082,04$ \\
$\begin{array}{l}\text { Budidaya } \\
\text { Industri) }\end{array}$ & 61,58 & 57,24 & 3,02 & 164,37 & - & 26,53 & 376,56 & 569,44 & 151,87 & $1.410,60$ \\
\hline Total & 214,56 & 124,90 & 44,67 & $1.065,60$ & 7,03 & 53,52 & 475,41 & $1.419,41$ & $1.170,37$ & $4.575,48$ \\
\hline
\end{tabular}

Berdasarkan Tabel 1 dapat dilihat bahwasannya pada ekosistem mangrove di Kecamatan Percut Sei Tuan telah terjadi perubahan penutupan lahan.Lanskap hutan mangrove pada tahun 2011 terindentifikasi seluas 1.140,37 ha tetapi menurun pada tahun 2016 menjadi 1.062,94 ha atau berkurang 77,43 ha. Hal ini berarti laju deforestasi di lanskap hutan mangrove Percut Sei Tuan sebesar 15,49 ha/tahun.

Pola pemanfaatan lahan pada ekosistem mangrove yang terjadi di Kecamatan Percut Sei Tuan tidak sesuai peruntukan penggunaan lahan seperti pada RTRW Kabupaten Deli Serdang (Tabel 2). Pada tahun 2016 peruntukan untuk hutan lindung sebesar 2.082,83 ha, tetapi pada kenyataan di lapangan tinggal 580,82 (27,95\%) saja yang sesuai karena masih bervegetasi mangrove, selebihnya tidak sesuai. Demikian juga peruntukan untuk hutan produksi terbatas, dari $1.082,04$ ha yang diperuntukan sebagai hutan produksi terbatas pada kenyataanya hanya 320,42 ha $(29,61 \%)$ saja yang masih bervegetasi mangrove.

\section{Pembahasan}

Ekosistem mangrove yang dimaksud dalam penelitian ini adalah daerah yang mempunyai landsystem KJP, KHY serta PTG.Ketiga tipe landsystem ini adalah daerah dimana hutan mangrove berpotensi dapat tumbuh dengan baik. Lanskap hutan mangrove existing merupakan bagian dari ekosistem mangrove. Pada kenyataanya kondisi di lapangan, ekosistem mangrove sudah tidak didominasi oleh lanskap hutan mangrove (lihat tabel 1).Ekosistem mangrove sebagian besar didominasi oleh penutupan lahan bukan mangrove, hal ini terjadi baik pada tahun 2011 maupun tahun 2016.

Lanskap hutan mangrove pada tahun 2011 terindentifikasi 24,92\%, sedangkan pada tahun 2016 lanskap hutan mangrove yang terindentifikasi tinggal $23,23 \%$. Perkebunan sawit dan tambak menjadi penutupan lahan yang dominan pada ekosistem mangrove di Kecamatan Percut Sei Tuan.Perubahan penutupan lahan mangrove menjadi perkebunan sawit dan tambak di Kecamatan Percut Sei Tuan menjadi penyebab deforestasi terbesar pada periode 2011-2016.

Terjadinya perubahan penutupan lahan di ekosistem mangrove Percut Sei Tuan ini menyebabkan ketidak sesuaian antara penutupan lahan existing dibandingkan dengan peruntukan penggunaan lahannya. Deforestasi banyak terjadi pada daerah-daerah yang aksesibilitasnya mudah seperti kedekatan dengan pemukiman dan kedekatan dengan jalan. Hal ini sesuai dengan hasil penelitian [8] dimana deforestasi di hutan Sumatera banyak terjadi pada daerah-daerah yang dekat dengan jalan yang mempunyai aksesibilitas mudah.

\section{Kesimpulan dan Saran}

Penggunaan citra satelit resolusi tinggi sangat efisien dan efektif untuk mendeteksi deforestasi lanskap hutan mangrove. Lanskap hutan mangrove di Kecamatan Percut Sei Tuan telah mengalami proses deforestasi dengan laju 
deforestasi sebesar 40,75 ha/tahun. Penggunaan lahan di Kecamatan Percut Sei Tuan tidak sesuai dengan pola peruntukannya, hal ini mendorong terjadinya kerusakan lanskap hutan mangrove yang ada.

\section{Ucapan Terima Kasih}

Ucapan terima kasih kami tujukan kepada Dana Non PNBP USU atas pendanaan yang telah diberikan kepada penulis sehingga penelitian ini dapat dilakukan. Makalah ini merupakan bagian dari skema Penelitian Terapan (PT) tahun 2017 penulis yang berjudul Pola Dan Pemodelan Spasial Deforestasi Di Lanskap Hutan Mangrove dengan nomor kontrak 104/UN5.2.3.1/PPM/KP-TALENTA USU/2017.

\section{Referensi}

[1] Onrizal. (2013) Mangrove: sumberdaya alam penting yang terancam. Wanamina 3 (1), 1-9.

[2] Ilman M, Dargusch P, Dart P, \& Onrizal. (2016) A historical analysis of the drivers of loss and degradation of Indonesia's mangroves. Land Use Policy 54, 448-459

[3] Holmes D, Rombang WM. 2001. Daerah Penting Bagi Burung: Sumatera. Bogor: PKA/BirdLife International-Indonesia Programme.

[4] Alkan Ma., Oruç, Ma., Kayabaşı D, and Sefercik UG 2010 Spatial And Temporal Gis Analysis Of Change Detection Using Ikonos Images: A Case Study Of Zonguldak ISPRS Istanbul Workshop 2010 on Modeling of optical airborne and spaceborne Sensors, WG I/4, Oct. 11-13, IAPRS Vol. XXXVIII-1/W17.

[5] Abdelwahed AM, Farrag FA, Abdelhafiz A, and Besheer MA 2011 Potential Of Using High Resolution Satellite Images For Mapping Applications, Journal of Engineering Sciences, Assiut University, Vol. 39, No 3, pp.513 -528, May 2011

[6] Churches CE, Wampler PJ, Sun W, Smith AJ. 2014. Evaluation of forest cover estimates for Haiti using supervised classification of Landsat data. 71

[7] Olofsson, G. M. Foody, M. Herold, S. V. Stehman, C. E. Woodcock, and M. A. 2014. Wulder, "Good practices for estimating area and assessing accuracy of land change," Remote Sensing of Environment, vol. 148, pp. 42-57.

[8] Sulistiyono N, Jaya INS, Prasetyo L, Tiryana T. 2015. Spatial Model of Deforestation in Sumatra Islands Using Typological Approach. Journal of Tropical Forest Management.Volume 21 no.3 hal: 99-109. doi. 10.7226/jtfm.21.3.99 